\title{
Mfsd14a (Hiat1) gene disruption causes globozoospermia and infertility in male mice
}

\author{
Joanne Doran ${ }^{1}$, Cara Walters ${ }^{2}$, Victoria Kyle ${ }^{2}$, Peter Wooding ${ }^{2}$, Rebecca Hammett-Burke ${ }^{2}$ \\ and William Henry Colledge ${ }^{2}$ \\ ${ }^{1}$ Takeda Cambridge Ltd, Cambridge, UK and '2Department of Physiology, Development and Neuroscience, \\ University of Cambridge, Cambridge, UK \\ Correspondence should be addressed to W H Colledge; Email:whc23@cam.ac.uk
}

\begin{abstract}
The Mfsd14a gene, previously called Hiat1, encodes a transmembrane protein of unknown function with homology to the solute carrier protein family. To study the function of the MFSD14A protein, mutant mice (Mus musculus, strain 129S6Sv/Ev) were generated with the Mfsd14a gene disrupted with a LacZ reporter gene. Homozygous mutant mice are viable and healthy, but males are sterile due to a 100-fold reduction in the number of spermatozoa in the vas deferens. Male mice have adequate levels of testosterone and show normal copulatory behaviour. The few spermatozoa that are formed show rounded head defects similar to those found in humans with globozoospermia. Spermatogenesis proceeds normally up to the round spermatid stage, but the subsequent structural changes associated with spermiogenesis are severely disrupted with failure of acrosome formation, sperm head condensation and mitochondrial localization to the mid-piece of the sperm. Staining for $\beta$-galactosidase activity as a surrogate for Mfsd14a expression indicates expression in Sertoli cells, suggesting that MFSD14A may transport a solute from the bloodstream that is required for spermiogenesis.

Reproduction (2016) 152 91-99
\end{abstract}

\section{Introduction}

Spermatogenesis is the developmental process by which spermatozoa are produced from spermatogonial germ cells in the gonads (Grootegoed et al. 1995, Jan et al. 2012). At the start of this process, spermatogonial cells give rise to primary spermatocytes, which progress through meiosis to produce haploid spermatids. The spermatids subsequently undergo spermiogenesis, a complex series of morphological changes to form spermatozoa (Toshimori \& Ito 2003). During spermiogenesis, chromatin condensation and nuclear remodelling occur, and also formation of the acrosome that contains glycosylated enzymes essential for egg fertilization. The acrosome is formed by the fusion of proacrosomal vesicles derived from the Golgi apparatus, which fuse to form a cap structure over the nucleus. A flagellum with the central $9+2$ microtubular axoneme is also formed during spermiogenesis and contains a mid-piece packed with mitochondria to provide energy for motility.

Defects in spermiogenesis contribute to male infertility problems in humans. Globozoospermia is one such syndrome that is found in around $0.1 \%$ of infertile men (Dam et al. 2007a). The disorder is characterized by round-headed sperm with a disrupted acrosome and abnormal mitochondrial localization. Genes that cause globozoospermia have been identified in mutant mice, which include Atg7 (Wang et al. 2014), Csnk2a2 (Xu et al. 1999), Dpy19/2 (Pierre et al. 2012), Gopc (Yao et al. 2002), Agfg1 (Hrb) (Kang-Decker et al. 2001), Hsp19ק1 (Audouard \& Christians 2011), Pick1 (Xiao et al. 2009), Smap2 (Funaki et al. 2013), Spaca1 (Fujihara et al. 2012) and Vps54 (Paiardi et al. 2011). Similarly, causative mutations of globozoospermia have been identified in humans including DPY19L2 (Harbuz et al. 2011, Koscinski et al. 2011), PICK1 (Liu et al. 2010) and SPATA16 (Dam et al. 2007b).

The Mfsd14a (a.k.a. Hiat1) gene was originally identified as an abundant transcript isolated from a fetal mouse hippocampus cDNA library (Matsuo et al. 1997) and classified as a member of the major facilitator superfamily of solute carrier proteins (SLCs) (Sreedharan et al. 2011). The SLC's consist of a large group of proteins capable of transporting diverse substances including amino acids, sugars, nucleosides and fatty acids (Hediger et al. 2004). The Mfsd14a gene shows modest sequence homology with the $E$. coli tetracycline-resistant protein class C $(31 \%)$ and with the mouse GLUT2 and GLUT4 glucose transporters (29\%). Furthermore, the protein has a similar structure to existing sugar transporters including 12-transmembrane spanning $\alpha$-helices, a $\mathrm{D}-\mathrm{R} / \mathrm{K}-\mathrm{X}-\mathrm{G}-\mathrm{R}-\mathrm{R} / \mathrm{K}$ motif between the $2 \mathrm{nd}$ and $3 \mathrm{rd}$ 
transmembrane domains and a region similar to the facilitative glucose transporter specific P-E-S-P-R motif at the end of the 6th transmembrane domain. These characteristics suggest that the Mfsd14a gene may encode a novel sugar transporter, but the solute specificity of the protein is not known.

To establish the physiological function of the MFSD14A protein in vivo, we generated a transgenic mouse line with a $L a c Z$ gene insertion that disrupts the expression of the Mfsd14a gene. Phenotypic characterization of these mutant mice indicated that the MFSD14A protein is required for the spermiogenesis stage in sperm formation, whereby round spermatids are structurally remodelled into spermatozoa.

\section{Materials and methods}

\section{Gene targeting and generation of mutant mice}

The transgenic mice were generated by standard methods in collaboration with Takeda Cambridge. The targeting vector was constructed using homology arms amplified from 129S6Sv/Ev mouse genomic DNA using the following primers:

5'armF: CCAACAAATAAGAGAGCGCTGCCTGTG;

5'armR: ACCAATAAGTGGGGCACTGAGGAATG;

3'armF: CTCTGATGAAGATCAGCCCGTGGTAAG;

3'armR: GCAGTAAGCCAGCCTGGGTATAGTAAAG.

The 5 'armF/R primers amplified a $1.54 \mathrm{~kb}$ fragment, and the 3 'armF/R primer pair amplified a $3.9 \mathrm{~kb}$ fragment. The arms were cloned on either side of a cassette containing an IRESLacZ reporter gene and a promoted neomycin phosphoribosyltransferase selectable marker gene. Homologous recombination of this targeting construct results in the deletion of $70 \mathrm{bp}$ of exon 4 of the Mfsd14a locus, which changes the coding frame to one that contains 23 stop codons and terminates translation of the MFSD14A protein at Glycine 93.

ES cells (CCB; 129S6/SvEv strain) were cultured, and gene targeting was performed as described previously (Ratcliff et al. 1992). Targeted clones were identified by PCR. Chimaeras were generated by injection into C57/Bl6 blastocysts, and inbred mice were established by breeding germline chimeras with $129 \mathrm{~S} 6 \mathrm{~Sv} / \mathrm{Ev}$ mice.

\section{Animals \\ All experiments were performed in accordance with the rele- vant guidelines and regulation under the authority of a United Kingdom Home Office Project Licence and were approved by the Local Ethical Review Committee of the University of Cambridge.}

\section{Genotyping transgenic mice}

Mice were genotyped by PCR using genomic DNA from ear biopsies. Genotyping primers were as follows:

Mutant Mfsd14a allele, Forward Primer: GTCTGGGACCAGCCCTTTAT
Mutant Mfsd14a allele, Reverse Primer: TGGCGAAAGGGGGATGTG

Wild-type Mfsd14a allele, Forward Primer: GTCTGGGACCAGCCCTTTAT

Wild-type Mfsd14a allele, Reverse Primer: ACGAGCAGGTAAAGGCTCAA

\section{RT-PCR}

Total RNA was prepared from testes using an SV Total RNA Isolation kit Z3101 (Promega) and converted into cDNA using a GoScript Reverse Transcription Kit, A5000 (Promega) according to the manufacturer's instructions. All primer pairs spanned introns to eliminate any amplification from genomic DNA, and RNA samples were included without a reverse transcription step as a negative control. The primer pairs were the following: $\mathrm{mHprtF}$ (CAGGCCAGACTTTGTTGGAT)/mHprtR (TTGCGCTCATCTTAGGCTTT), 147 bpproduct; mMfsd14aEx1F (ATGACCCAGGGGAAGAAAAAG)/m Mfsd 14 aEx3 R (GGTTTCATGCAATACCACCA), 195 bpproduct; mMfsd14aEx4F (GTTTGGGGCCGAAAGTCC) mMfsd14aEx5R (GCAAAAACCCCAGAAACAGA), 119 bp product.

The amplification cycle was $95^{\circ} \mathrm{C}, 5 \mathrm{~min},\left(93^{\circ} \mathrm{C}, 0.5 \mathrm{~min}\right.$, $\left.60^{\circ} \mathrm{C}, 0.5 \mathrm{~min}, 70^{\circ} \mathrm{C}, 1 \mathrm{~min}\right) \times 40$.

\section{Sperm and germ cell counts}

Mice were killed and sperm isolated from a fixed length of the vas deferens by squeezing into $100 \mu \mathrm{L}$ of $1 \%$ PBS. A $25 \mu \mathrm{L}$ sample was loaded onto a haemocytometer and the number of sperm was counted. For quantitation of germ cells, haematoxylin- and eosin-stained sections at stages IV/V/VI of the seminiferous cycle were photographed at the same magnification and the number of each germ cell type was counted in a $100 \times 200 \mu \mathrm{m}$ rectangle drawn on the photomicrograph. Counts were made from 49 rectangles for wild-type mice $(n=4)$ and from 48 rectangles for mutant mice $(n=4)$.

\section{Testosterone ELISA}

Total plasma testosterone levels were measured in wild-type and mutant mice at approximately 3 months of age using a commercially available ELISA kit (DRG International, USA, EIA-1559) according to the manufacturer's instructions. The analytical sensitivity of the ELISA was $0.083 \mathrm{ng} / \mathrm{mL}$, the intra-assay variation was $3.2 \%$ and the inter-assay variation was $6.7 \%$. Blood $(100 \mu \mathrm{L})$ was collected from the vena cava and mixed with $2 \mu \mathrm{L} 0.5 \mathrm{M}$ ethylenediaminetetracetic acid (EDTA) anti-coagulant. Plasma was obtained by centrifugation of the sample at $16,500 \mathrm{~g}$ for $5 \mathrm{~min}$ and stored at $-80^{\circ} \mathrm{C}$ until assayed. Plasma samples were assayed without further extractions, so that the free testosterone levels were measured.

\section{Histology}

Tissues were fixed in 4\% paraformaldehyde/PBS overnight at $4^{\circ} \mathrm{C}$, dehydrated through graded alcohols and embedded in 
wax or epoxy resin for histological sectioning. Wax sections were cut at $7 \mu \mathrm{m}$ and stained with haematoxylin and eosin. For the visualization of acrosome formation, resin sections $(1 \mu \mathrm{m})$ were stained with $1 \%$ toluidine blue in $70 \%$ ethanol. Mitochondria were visualized with MitoTracker Green (Invitrogen). To detect $\beta$-galactosidase activity, tissues were fixed in $4 \%$ paraformaldehyde/PBS for $30 \mathrm{~min}$, washed in PBS and incubated overnight at $37^{\circ} \mathrm{C}$ in LacZ stain $(5 \mathrm{mM}$ potassium ferricyanide, $5 \mathrm{mM}$ potassium ferrocyanide in PBS, $20 \mathrm{mg} / \mathrm{mL}$ $X$-gal stock and $1 \mathrm{mM} \mathrm{MgCl}_{2}$ ). The samples were post-fixed in $4 \%$ paraformaldehyde/PBS before embedding in wax and sectioning. For electron microscopy, tissues were fixed in 4\% glutaraldehyde, post-fixed in 1\% osmium tetroxide, en blocstained with $2 \%$ uranyl acetate, dehydrated and embedded in Spurr's epoxy.

\section{Statistical analysis}

The statistical tests are indicated in the figure legends. For data sets that did not pass a normality test, a non-parametric test was used (two-tailed, Mann-Whitney). A $P$ value of less than 0.05 was considered to be significant.

\section{Results}

The Mfsd14a gene was disrupted by gene targeting in mouse ES cells to remove $70 \mathrm{bp}$ of coding sequence from exon 4 and insert an IRES (Internal Ribosome Entry Site)-LacZ-Neo reporter gene (Fig. 1A). Transgenic mutant mice carrying this targeted Mfsd14a allele (designated Mfsd14 $\mathrm{a}^{\text {tm1Coll }}$ ) were generated and tested by RT-PCR to confirm a null allele (Fig. 1B). RT-PCR between exons upstream of the insertion (P1F/P3R) generated the expected $195 \mathrm{bp}$ product in both wild-type and mutant mice (Fig. 1B). RT-PCR across the insertion site, between exons 3 and 5, generated a $197 \mathrm{bp}$ product in wild-type mice and a $69 \mathrm{bp}$ product in mutant mice (Fig. 1B). Sequence analysis of the PCR product from the mutant mice indicated that this was from mRNA that had spliced between exons 3 and 5. RT-PCR using a forward primer located within the $70 \mathrm{bp}$ deleted sequence and a downstream primer (P4F/P5R) gave an $119 \mathrm{bp}$ product in wild-type but no product in the mutant mice, indicating that no wild-type transcripts were present in the
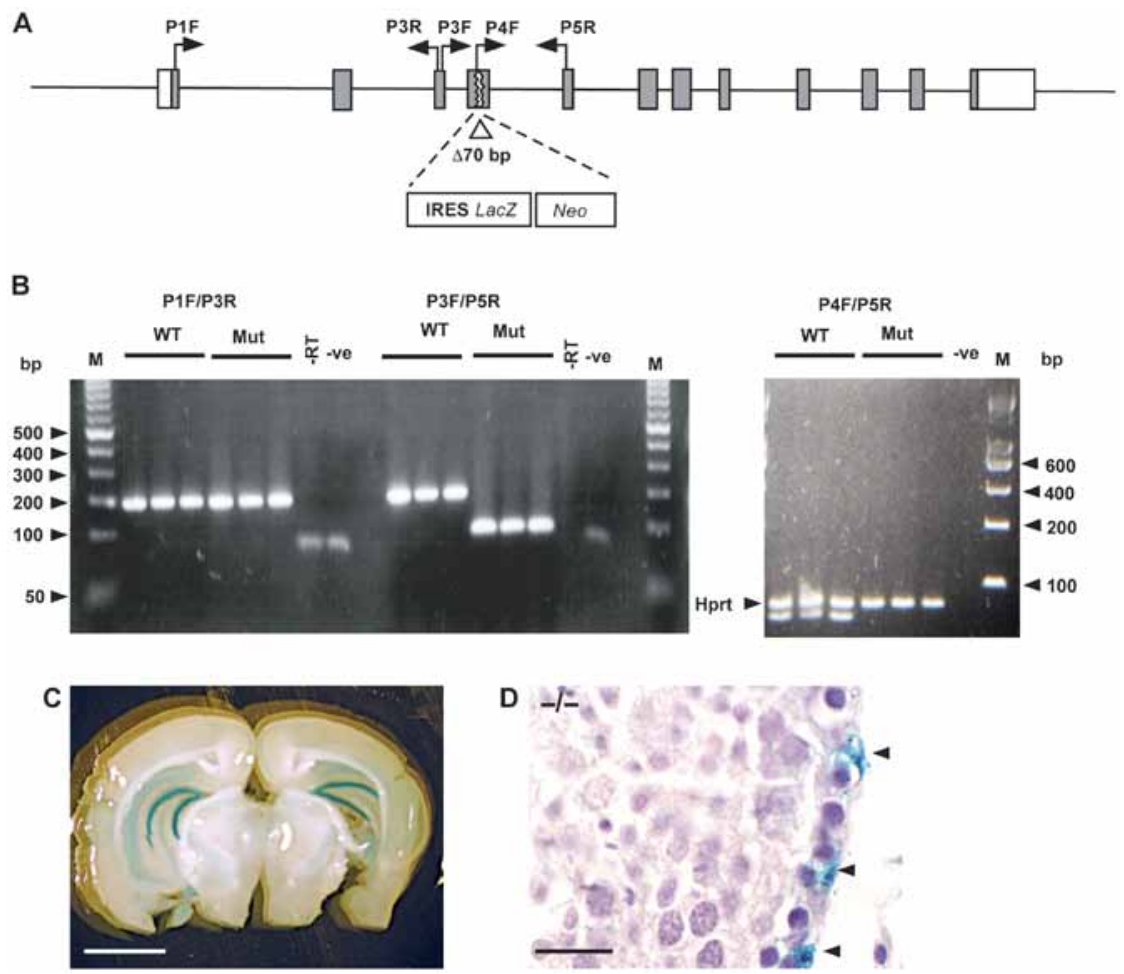

Figure 1 Molecular characterization of Mfsd14a-mutant mice. (A) Targeted Mfsd14a allele. The Mfsd14a gene consists of 12 exons (coding regions shaded). A 70 bp deletion was introduced into exon 4 and an internal ribosome entry sequence (IRES)-LacZ transgene was inserted to detect Mfsd14a gene expression by staining for $\beta$-galactosidase activity. Primer locations are indicated by arrows. (B) Confirmation of a null allele by RT-PCR of RNA from testes. PCR between exons upstream of the insertion (P1F/P3R) amplified products in wild-type and homozygous mutant samples. PCR amplification across exon 4 (P3F/P5R) gave a PCR product in the mutant that was generated from transcripts spliced between exons 3 and 5. PCR amplification downstream of the insertion (P4F/P5R) did not give a product in the mutant samples. Hprt was included as a positive control for the PCR reaction. $-\mathrm{RT}$, no reverse transcriptase; - ve, no template control. M, Bioline $1 \mathrm{~kb}$ DNA marker. (C) Mfsd14a gene expression in the hippocampus visualized by $\beta$-galactosidase staining (blue). Scale bar $=0.25 \mathrm{~cm}$. (D) Mfsd14a gene expression in the testes of mutant (-/-) mice visualized by $\beta$-galactosidase staining (blue). Staining was found in the cytoplasm of Sertoli cells (arrowheads indicate Sertoli cell nuclei). Scale bar $=50 \mu \mathrm{m}$. 
Table 1 Relative tissue weights of Hiat1-mutant mice compared with age-matched wild-type mice.

\begin{tabular}{lcccccccc}
\hline & & \multicolumn{5}{c}{ Relative tissue weights $(\mathrm{g})$} \\
\cline { 3 - 8 } Genotype & Age/days & Body & Liver & Kidney & Testis & $\begin{array}{c}\text { Epididymis (head, } \\
\text { body and tail) }\end{array}$ & Vas deferens & Seminal vesicle \\
\hline WT $(n=9)$ & $157 \pm 11$ & $28.9 \pm 1.8$ & $0.99 \pm 0.09$ & $0.18 \pm 0.006$ & $0.098 \pm 0.025$ & $0.0278 \pm 0.001$ & $0.015 \pm 0.006$ & $0.12 \pm 0.009$ \\
Mutant $(n=8)$ & $158 \pm 21$ & $26.6 \pm 2.0$ & $0.97 \pm 0.09$ & $0.20 \pm 0.011$ & $0.073 \pm 0.002$ & $0.0273 \pm 0.003$ & $0.011 \pm 0.008$ & $0.09 \pm 0.007$ \\
$P$ value median & 0.353 & $0.046^{*}$ & 0.42 & 0.09 & 0.74 & 0.69 & 0.96 & $0.046^{*}$ \\
\hline
\end{tabular}

Tissue weights were normalized to body weight and calculated for a $25 \mathrm{~g}$ mice. Values are mean \pm S.E.M. $P$ values were calculated using a Mann-Whitney, two-tailed $t$-test. *indicates a statistically significant difference $(P<0.05)$.

mutant mice (Fig. 1B). All PCR products were sequenced to confirm their identity.

The disrupted Mfsd14a allele contains an IRES-LacZ reporter gene, which is expressed from the endogenous Mfsd14a promoter (Fig. 1A). This allows the expression profile of the Mfsd14a gene to be examined at the cellular level by staining tissues for $\beta$-galactosidase activity. This is useful as no suitable antibodies are available to visualize the expression of the MFSD14A protein by immunohistochemistry. Expression of the Mfsd14a gene was confirmed in the hippocampus (Fig. 1D) as previously reported (Matsuo et al. 1997). Mfsd14a gene expression was also found in the testes with the distribution of $\beta$-galactosidase activity often spread throughout the seminiferous tubule and highest close to Sertoli cell nuclei (Fig. 1D, arrowed). These observations are consistent with Mfsd14a expression in Sertoli cells with no indication of expression in germ cells.

The Mfsd14a-mutant mice were overtly healthy with no obvious signs of any detrimental phenotype. Mutant females were fertile, but mutant males were sterile. The average body weight of the mutant male mice was slightly slower than that of the age-matched wild-type mice $(26.6 \pm 2.0 \mathrm{~g}$ vs $28.9 \pm 1.8 \mathrm{~g}$, Table 1$)$. Consequently, tissue weights were normalized relative to body weight (Table 1). There were no significant differences between wild-type and mutant mice in the relative weights of the liver, kidney, testis, epididymis or vas deferens, but the weight of the seminal vesicle was slightly less in the mutant mice (Table 1). Free testosterone levels were not significantly different between mutant and wild-type mice, although two wild-type mice had higher levels than the rest of the cohort (Fig. 2A). The mutant mice showed normal copulatory behaviour and produced vaginal plugs after mating (Fig. 2B). The number of sperm that could be isolated from the vas deferens was around 100 -fold lower in the mutant mice $\left(5.0 \times 10^{6} \pm 1.0 \times 10^{6}\right)$ compared with wild type $\left(4.3 \times 10^{8} \pm 5 \times 10^{7}\right)$ (Fig. 2C). Quantitation of each type of germ cell in the testes at stage $V$ of the seminiferous cycle indicated that there was no difference in the number of spermatogonia, primary spermatocytes or round spermatids, but the number of elongating spermatids was significantly lower in the mutant mice (Fig. 2D).

Histological analysis of the testes of mutant mice showed that the process of spermiogenesis was severely disrupted. The mutant mice showed dysmorphic sperm head formation with abnormal nuclear condensation (Fig. 3B) compared with the condensed heads of wildtype mice (Fig. 3A, arrowed). The mutant sperm showed the formation of a tail however (Fig. 3J). The number of sperm in the epididymis of the mutant mice was less than that in wild-type mice (Fig. 3C and D), and the round-headed shape of the sperm with residual cytoplasm was clearly visible. Toluidine blue staining for glycoproteins showed that the mutant sperm did not form an acrosome compared with the normal acrosomal cap
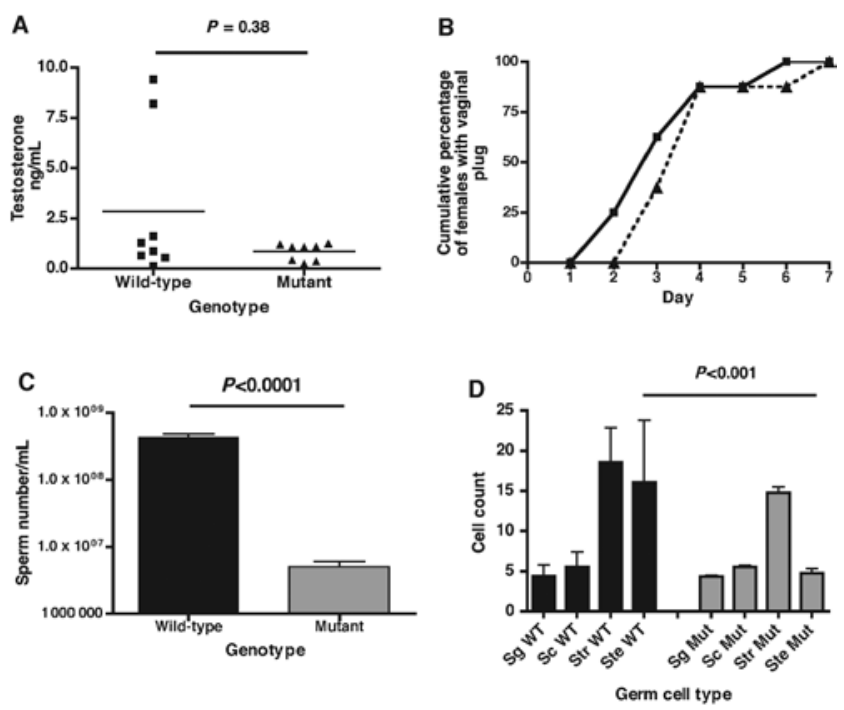

Figure 2 Reproductive phenotype of mutant Mfsd14a male mice. (A) Plasma testosterone levels. Plasma testosterone concentrations were measured from terminal blood samples by ELISA. No significant difference was found between mutant $(n=8)$ and wild-type males $(n=8)$ ( $P=0.38$, Mann-Whitney test). (B) Copulatory plugging rate. Mfsd14a-mutant mice $(n=8)$ and control wild-type $(n=8)$ males were housed singly with a wild-type female each and checked daily for a copulatory plug in the vagina. (C) Sperm counts. Sperm were isolated from the vas deferens of mutant $(n=8)$ and wild-type $(n=8)$ mice and counted. Mutant mice had a significantly lower number of sperm $(P<0.0001$, unpaired $t$-test with Welch correction). (D) Germ cell numbers. The number of cells in each germ cell category within seminiferous tubule sections at stages IV/V/VI of the seminiferous cycle was counted. Sg, spermatogonia; Sc, primary spermatocytes; Str, round spermatids; Ste, elongating spermatids. ( $n=4$ for wild-type and mutant mice). The only significant difference was between the numbers of elongating spermatids $(P<0.001$, Mann-Whitney test). 

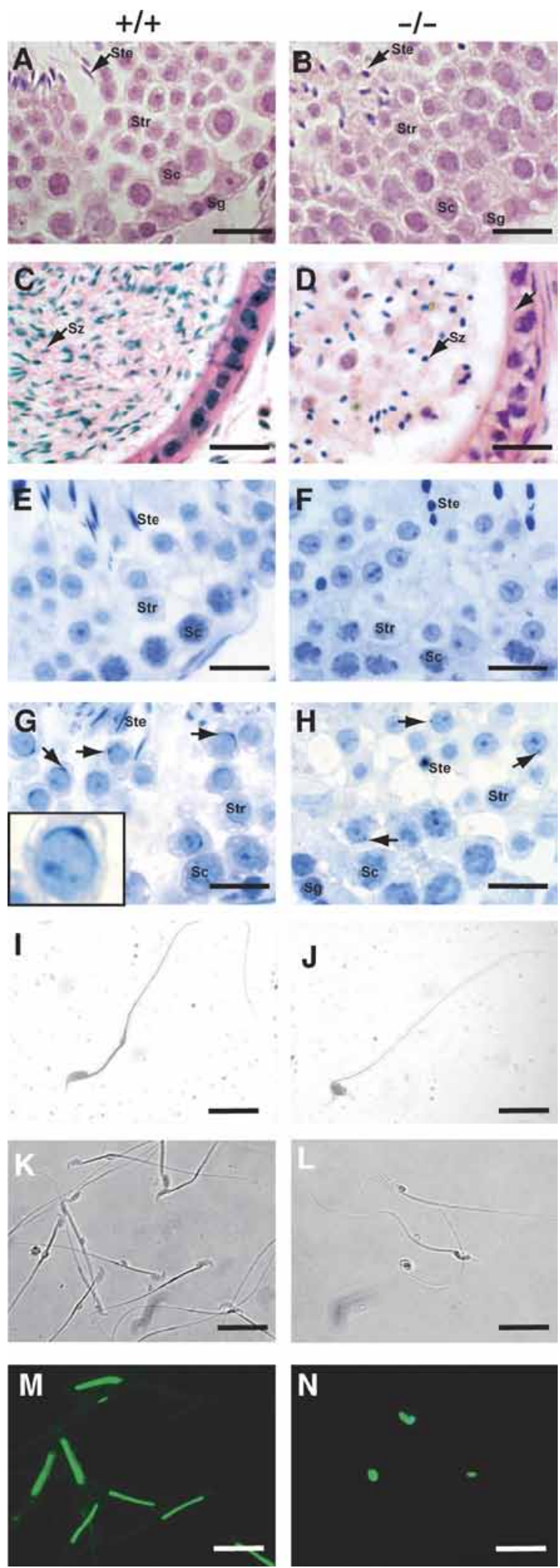

Figure 3 Defective spermiogenesis and globozoospermia in Mfsd14a-mutant mice. (A) Spermatogenesis in wild-type testis showing normal condensation of sperm heads (arrowed) after spermiogenesis. Scale bar $=50 \mu \mathrm{m}$. (B) Defective spermiogenesis in mutant testis with spermatozoa showing rounded heads (arrowed). over the nucleus of the wild-type sperm (Fig. 3G and H). At stage I of the seminiferous cycle, before any acrosome development, step 1 spermatids appeared identical in wild-type and mutant testes (Fig. 3E and F). By contrast, at stage VI of the seminiferous cycle, the acrosome is clearly visible in the wild-type mice (Fig. 3G), but no acrosome has formed in the mutant mice (Fig. 3H). Small vesicles that stain for glycoproteins are found in the mutant mice, suggesting a defect in vesicular trafficking from the Golgi and/or fusion with the developing acrosome. Sperm isolated from the vas deferens of mutant mice showed a round head, irregular-shaped nucleus and absence of a distinct mid-piece compared with wild-type sperm (Fig. 3I and J). Wild-type sperm showed normal localization of mitochondria to the midpiece (Fig. 3K and M). By contrast, mutant sperm failed to localize mitochondria to the mid-piece, and mitochondria were often found in the head region (Fig. $3 \mathrm{~L}$ and $\mathrm{N}$ ).

Ultrastructural analysis by transmission electron microscopy confirmed the light microscopy findings that the morphological changes associated with spermiogenesis were disrupted in the mutant mice. At Step 1 of spermiogenesis, no obvious difference was observed between normal and mutant spermatids (Fig. 4A). By Step 6 of spermiogenesis, wild-type sperm showed the early stage of acrosome formation with a single pro-acrosomal granule within the growing acrosome (Fig. 4B). By contrast, the mutant mice show no acrosome formation and the presence of several small proacrosomal granules (Fig. 4B). Both wild-type and mutant mice show a thickening of the nuclear membrane opposite the Golgi complex that gives rise to the acrosomal

Scale bar $=50 \mu \mathrm{m}$. (C) Resin section of epididymis from wild-type mice showing large numbers of normal sperm with hook-shaped heads (arrowed). Scale bar $=50 \mu \mathrm{m}$. (D) Resin section of epididymis from mutant mice showing severely reduced sperm numbers with round heads (arrowed) and failure to remove excess cytoplasm. Scale bar $=50 \mu \mathrm{m}$. (E and F) Resin sections of stage I seminiferous tubules showing similar appearance of Step 1 spermatids and round-headed spermatozoa in mutants (F). Toluidine blue stain. Scale bars $=25 \mu \mathrm{m}$. $(\mathrm{G}$ and $\mathrm{H}$ ) Resin sections of stage $\mathrm{VI}$ seminiferous tubules showing acrosome cap formation in wild type (deep blue stain, arrowed, high power insert) but no acrosome formation in the mutants with occasional vesicle accumulation (arrowed). Toluidine blue stain. Scale bar $=25 \mu \mathrm{m}$. (I) Normal morphology of sperm from wild-type mouse epididymis. Scale bar $=20 \mu \mathrm{m}$. (J) Round head morphology of sperm isolated from mutant mouse epididymis. Scale bar $=20 \mu \mathrm{m}$. ( $\mathrm{K}$ and $\mathrm{M}$ ) Location of mitochondria in mid-piece of sperm from wild-type mice visualized by MitoTracker Green stain. (I) phase contrast; (K) fluorescence. Scale bar $=40 \mu \mathrm{m}$. ( $\mathrm{L}$ and N) Failure of mitochondria to correctly localize to mid-piece region of sperm in mutant mice visualized by MitoTracker Green stain. The mitochondria often remain in the residual cytoplasm that is not correctly removed from the sperm head. J, phase contrast; $\mathrm{L}$, fluorescence. Scale bar $=40 \mu \mathrm{m}$. Sg, spermatogonium;

Sc, spermatocyte; Str, round spermatid; Ste, elongating spermatid; $\mathrm{Sz}$, spermatozoon. 

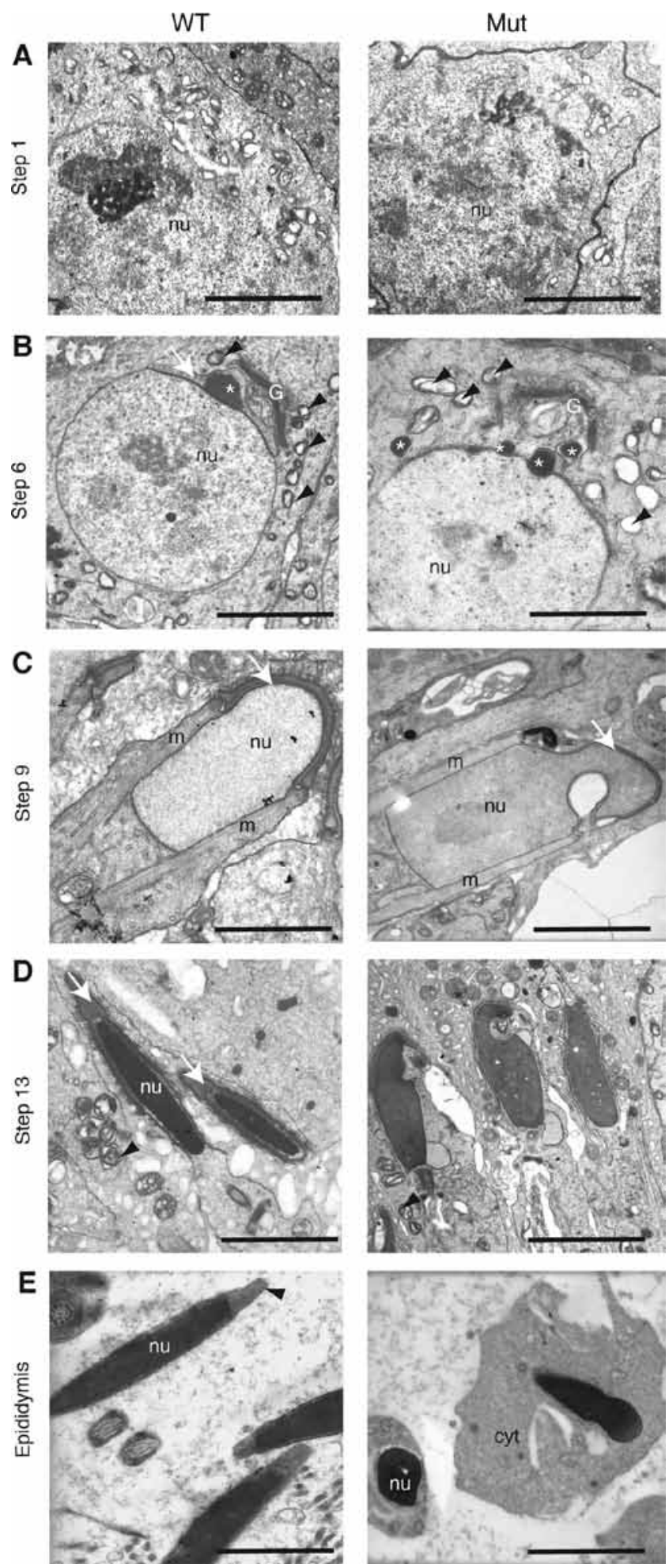

Figure 4 Ultrastructural analysis of spermiogenesis in Mfsd14amutant mice. Transmission electron microscopy illustrating different stages of spermiogenesis in wild-type (+/+) and mutant (-/-) mice. Micrographs were staged according to Russell and coworkers (1990). All scale bars $=5 \mu \mathrm{M}$. (A) Step 1 spermatids showing no obvious difference between mutant and wild type. nu, nucleus. (B) Step 6 spermatid showing juxtanuclear Golgi apparatus (G) and formation of the acrosomal cap (white arrow) with a single proacrosomal granule vesicles, suggesting correct formation of the acroplaxome. Mitochondria were found in the head of both wild-type and mutant sperm at this stage. By Step 9 of spermiogenesis, the sperm heads showed considerable morphological remodelling, with condensation and elongation of the nucleus, and removal of excess cytoplasm (Fig. 4C). At this stage, the manchette, a microtubule structure involved in nuclear reshaping (Yoshida et al. 1994), was clearly visible. At Step 9, mutant sperm had no acrosome formation and the nuclear remodelling was disrupted with abnormal vacuolation of the nucleus, but they showed formation of the manchette (Fig. 4C). By Step 13, wild-type sperm showed the typical elongated sperm head shape with a clear acrosome (Fig. 4D). By contrast, the mutant sperm at this stage had irregular-shaped nuclei with mitochondria in close proximity and no obvious acrosome formation (Fig. 4D). Mutant sperm isolated from the epididymis showed round heads with residual cytoplasm (Fig. 4D), whereas the wild-type sperm had condensed heads with clear acrosomal caps and no residual cytoplasm.

\section{Discussion}

We have shown that the Mfsd14a gene is required for the final stages of spermatogenesis in mice, namely the structural remodelling of round spermatids into functional spermatozoa. Mutant mice have severely reduced sperm numbers in the vas deferens and are sterile. While this reduction in sperm numbers alone would render the mice sub-fertile, the lack of an acrosome will also prevent egg fertilization as the acrosome contains enzymes required for penetration through the zona pellucida of the egg. The number of sperm observed in the cauda epididymis is also reduced, suggesting that the release of sperm into the seminiferous tubules (spermiation) is impaired. Spermiation can be impaired by a low testosterone level (Beardsley \& O'Donnell 2003), but this is unlikely to be the case for the Mfsd14a-mutant mice

\footnotetext{
(asterisk) over the nucleus (nu) in the wild type. Several vesicles containing proacrosomal granules (asterisk) can be seen in the mutant but with no fusion to form the acrosome. Mitochondria are indicated by black arrowheads. (C) Late stage Step 9 spermatid in which the nucleus (nu) has become ovoid and the acrosomal cap expands to cover the nucleus (white arrow) in the wild type. Mutants have an abnormal nuclear shape and lack acrosome formation (white arrow). The manchette $(\mathrm{m})$ has formed in both the wild type and the mutants. (D) Step 13 of spermiogenesis showing condensed nuclear heads (nu) and acrosome (white arrow) in wild-type mice and misshapen and fragmented nuclei in the mutant mice with no apparent acrosome. Mitochondria are indicated by black arrowheads. (E) Spermatozoa in the epididymis showing condensed nuclei (nu) and overlaying acrosome cap (black arrowhead) in wild-type mice. Mutant spermatozoa showing abnormal-shaped nuclei and round heads (globozoospermia) with a failure to remove residual cytoplasm (cyt).
} 
as they have testosterone levels sufficient to allow the development of accessory sex organs and normal copulatory behaviour.

In the absence of a suitable antibody for immunohistochemistry, the expression profile of the targeted Mfsd14a gene was visualized by staining for $\beta$-galactosidase activity. The staining was consistent with expression in Sertoli cells rather than the germ cell themselves. $\beta$-galactosidase activity was found to extend throughout the inside of the seminiferous tubules, presumably within the Sertoli cell cytoplasm, but was also concentrated close to Sertoli cell nuclei in the peritubular compartment. Sertoli cells play a major role in supporting germ cell development, and Sertoli-germ cell junctions allow communication between these cell types. Disruption of acrosome formation by a Sertoli cell-specific gene defect is not unprecedented. For example, disruption of the Gba2 gene, which encodes a $\beta$-glucosidase enzyme located in the endoplasmic reticulum of Sertoli cells, results in round-headed sperm lacking acrosomes (Yildiz et al. 2006). $\beta$-glucosidase hydrolyses glucosylceramide, a glycolipid, into glucose and ceramide. In the Gba2mutant mice, glucosylceramide accumulates in the Sertoli cells, but it is not known if this is derived from the germ cells or produced by the Sertoli cells themselves. Whatever the mechanism, the Gba2-mutant mice illustrate that a Sertoli cell defect can result in globozoospermia.

Other mutant mice have been described with defects in acrosome biogenesis and globozoospermia, including those with disruption of the Atg7 (Wang et al. 2014), Csnk2a2 (Xu et al. 1999), Dpy19/2 (Pierre et al. 2012), Gopc (Yao et al. 2002), Agfg1 (Hrb) (Kang-Decker et al. 2001), Hsp19ק1 (Audouard \& Christians 2011), Pick1 (Xiao et al. 2009), Smap2 (Funaki et al. 2013), Spaca1 (Fujihara et al. 2012) and Vps54 (Paiardi et al. 2011) genes. The similarity in the phenotype of these mutant mice suggests that these genes form a functional network required for the ultrastructural changes to the sperm head. One common cell process in which several of these proteins are involved is vesicle trafficking in the cell. During acrosome formation, vesicles bud from the trans-Golgi network and bind to the acroplaxome, a mesh of cytoskeletal fibres covering the surface of the sperm nucleus (Kierszenbaum \& Tres 2004). These proacrosomal vesicles eventually fuse to form the acrosome. PICK and GOPC co-localize to trans-Golgi vesicles (Xiao et al. 2009) and PICK1 has been shown to bind to both GOPC and CK2 $\alpha 2$. The Atg7 gene encodes a protein that is required to localize GOPC to the transGolgi vesicles (Wang et al. 2014). Similarly, Smap2 encodes a GTPase-activating protein that interacts with clathrin (Natsume et al. 2006) and is required for vesicle budding from the trans-Golgi network (Funaki et al. 2013). Agfg1 also encodes a GTPase-activating protein which is localized to the cytoplasmic side of proacrosomal vesicles and is involved in their fusion (Kang-Decker et al. 2001). The Vps54 gene encodes a vesicle sorting protein involved in retrograde transport of endosomes to the trans-Golgi network.

Appropriate sorting, trafficking and fusion of intracellular vesicles to the correct sub-cellular location is a complex process involving many different proteins. How the MFSD14A protein fits into this pathway to regulate acrosome formation and sperm maturation is not yet known. Since the MFSD14A protein has homology to sugar transporters, it is possible that defects in protein or lipid glycosylation may play a role in this process. Glycosylation is an important post-translational modification important in sorting protein to different cell compartments. For example, mannose-6-phosphate residues on glycoproteins are important in targeting these proteins to lysosomes. It has been suggested that acrosome biogenesis is functionally related to the formation of secretory lysosomes (Hartree 1975, Moreno \& Alvarado 2006). The acrosome contains several enzymes that are also found in lysosomes (e.g. acid phosphatase, Cathep$\sin \mathrm{D}$ and $\mathrm{H}$ ) and the contents of both organelles are acidified by a vacuolar $\mathrm{H}^{+}$-pump (V-ATPase).

Interestingly, DPY19L2 is a putative C-mannosyltransferase based on homology to the $C$. elegans gene dumpy-19 (Dpy19). Dpy19L2-mutant mice do not form an acrosome and show defective chromatin compaction during spermiogenesis with defective transport of protamines into the nucleus (Yassine et al. 2015). Based on these data, one hypothesis is that MFSD14A is required for uptake of a sugar (e.g. mannose) from the bloodstream by the Sertoli cells, which is then used by spermatids for glycosylation of key molecules required for acrosome formation. It may be informative to perform a glycomic analysis of the Mfsd14a-mutant testes to gain an insight into the substance that is transported by this protein.

Our data show that the Mfsd14a gene is required for the structural remodelling events required to produce spermatozoa in mice. The MFSD14A protein sequence is very similar between mice and other species including mammals $(99.8 \%)$, reptiles $(95 \%)$, amphibians $(93 \%)$, birds $(84 \%)$ and fish $(82 \%)$. This suggests that the function of this protein is conserved across several classes of vertebrates. The mutant mice produce reduced sperm numbers with round heads very similar to those observed in infertile men with rare cases of globozoospermia (Dam et al. 2007a). The similarity between the sperm from the mutant mice and those produced in human globozoospermia extends to a failure to produce the acrosome and to correctly localize mitochondria to the mid-piece of the sperm. These close similarities suggest that some globozoospermia men will have mutations in the MFSD14A gene, and we are currently screening individuals for this mutation. 


\section{Declaration of interest}

The authors declare that there is no conflict of interest that could be perceived as prejudicing the impartiality of the research reported.

\section{Funding}

This research did not receive any specific grant from any funding agency in the public, commercial or not-for-profit sector. This work was funded by a Ford Physiology Fund Endowment (WHC).

\section{Author contribution statement}

J Doran and $\mathrm{W} \mathrm{H}$ Colledge generated the $\mathrm{KO}$ mouse line and J Doran originally identified the spermiogenesis defect. C Walters, V Kyle and R Hammett-Burke characterized the phenotype further. P Wooding performed the electron microscopy. W H Colledge designed the study and wrote the manuscript. All authors reviewed the manuscript.

\section{Acknowledgements}

The authors thank the biofacility staff, particularly Wendy, for exemplarity husbandry.

\section{References}

Audouard C \& Christians E 2011 Hsp90beta1 knockout targetted to male germline: a mouse model for globozoospermia. Fertility and Sterility $\mathbf{9 5}$ 1475-1477 e1471-1474. (doi:10.1016/j.fertnstert.2010.12.006)

Beardsley A \& O'Donnell L 2003 Characterization of normal spermiation and spermiation failure induced by hormone suppression in adult rats. Biology of Reproduction 68 1299-1307. (doi:10.1095/ biolreprod.102.009811)

Dam AH, Feenstra I, Westphal JR, Ramos L, van Golde RJ \& Kremer JA 2007a Globozoospermia revisited. Human Reproduction Update 13 63-75. (doi:10.1093/humupd/dml047)

Dam AH, Koscinski I, Kremer JA, Moutou C, Jaeger AS, Oudakker AR, Tournaye H, Charlet N, Lagier-Tourenne C, van Bokhoven H et al. 2007 b Homozygous mutation in SPATA16 is associated with male infertility in human globozoospermia. American Journal of Human Genetics $\mathbf{8 1}$ 813-820. (doi:10.1086/521314)

Fujihara Y, Satouh Y, Inoue N, Isotani N, Ikawa M \& Okabe M 2012 SPACA1-deficient male mice are infertile with abnormally shaped sperm heads reminiscent of globozoospermia. Development 139 3583-3589. (doi:10.1242/dev.081778)

Funaki T, Kon S, Tanabe K, Natsume W, Sato S, Shimizu T, Yoshida N, Wong WF, Ogura A, Ogawa T et al. 2013 The Arf GAP SMAP2 is necessary for organized vesicle budding from the trans-Golgi network and subsequent acrosome formation in spermiogenesis. Molecular Biology of the Cell 24 2633-2644. (doi:10.1091/mbc.E13-05-0234)

Grootegoed JA, Baarends WM, Hendriksen PJ, Hoogerbrugge JW, Slegtenhorst-Eegdeman KE \& Themmen AP 1995 Molecular and cellular events in spermatogenesis. Human Reproduction 10 10-14. (doi:10.1093/humrep/10.suppl_1.10)

Harbuz R, Zouari R, Pierre V, Ben Khelifa M, Kharouf M, Coutton C, Merdassi G, Abada F, Escoffier J, Nikas Y et al. 2011 A recurrent deletion of DPY19L2 causes infertility in man by blocking sperm head elongation and acrosome formation. American Journal of Human Genetics $\mathbf{8 8} 351$ 361. (doi:10.1016/j.ajhg.2011.02.007)

Hartree EF 1975 The acrosome-lysosome relationship. Journal of Reproduction and Fertility 44 125-126. (doi:10.1530/jrf.0.0440125)
Hediger MA, Romero MF, Peng JB, Rolfs A, Takanaga H \& Bruford EA 2004 The ABCs of solute carriers: physiological, pathological and therapeutic implications of human membrane transport proteins. Pflugers Archiv 447 465-468. (doi:10.1007/s00424-003-1192-y)

Jan SZ, Hamer G, Repping S, de Rooij DG, van Pelt AM \& Vormer TL 2012 Molecular control of rodent spermatogenesis. Biochimica et Biophysica Acta 1822 1838-1850. (doi:10.1016/j.bbadis.2012.02.008)

Kang-Decker N, Mantchev GT, Juneja SC, McNiven MA \& van Deursen JM 2001 Lack of acrosome formation in Hrb-deficient mice. Science 294 1531-1533. (doi:10.1126/science.1063665)

Kierszenbaum AL \& Tres LL 2004 The acrosome-acroplaxome-manchette complex and the shaping of the spermatid head. Archives of Histology and Cytology 67 271-284. (doi:10.1679/aohc.67.271)

Koscinski I, Elinati E, Fossard C, Redin C, Muller J, Velez de la Calle J, Schmitt F, Ben Khelifa M, Ray PF, Kilani Z et al. 2011 DPY19L2 deletion as a major cause of globozoospermia. American Journal of Human Genetics 88 344-350. (doi:10.1016/j.ajhg.2011.01.018)

Liu G, Shi QW \& Lu GX 2010 A newly discovered mutation in PICK1 in a human with globozoospermia. Asian Journal of Andrology 12 556-560. (doi:10.1038/aja.2010.47)

Matsuo N, Kawamoto S, Matsubara K \& Okubo K 1997 Cloning of a cDNA encoding a novel sugar transporter expressed in the neonatal mouse hippocampus. Biochemical and Biophysical Research Communications 238 126-129. (doi:10.1006/bbrc.1997.7252)

Moreno RD \& Alvarado CP 2006 The mammalian acrosome as a secretory lysosome: new and old evidence. Molecular Reproduction and Development 73 1430-1434. (doi:10.1002/(ISSN)1098-2795)

Natsume W, Tanabe K, Kon S, Yoshida N, Watanabe T, Torii T \& Satake M 2006 SMAP2, a novel ARF GTPase-activating protein, interacts with clathrin and clathrin assembly protein and functions on the AP-1positive early endosome/trans-Golgi network. Molecular Biology of the Cell 17 2592-2603. (doi:10.1091/mbc.E05-10-0909)

Paiardi C, Pasini ME, Gioria M \& Berruti G 2011 Failure of acrosome formation and globozoospermia in the wobbler mouse, a Vps54 spontaneous recessive mutant. Spermatogenesis 1 52-62. (doi:10.4161/ spmg.1.1.14698)

Pierre V, Martinez G, Coutton C, Delaroche J, Yassine S, Novella C, PernetGallay K, Hennebicq S, Ray PF \& Arnoult C 2012 Absence of Dpy19l2, a new inner nuclear membrane protein, causes globozoospermia in mice by preventing the anchoring of the acrosome to the nucleus. Development 139 2955-2965. (doi:10.1242/dev.077982)

Ratcliff R, Evans MJ, Doran J, Wainwright BJ, Williamson R \& Colledge WH 1992 Disruption of the cystic fibrosis transmembrane conductance regulator gene in embryonic stem cells by gene targetting. Transgenic Research 1 177-181. (doi:10.1007/BF02522536)

Russell LD, Ettlin RA, Sinha Hikim AP \& Clegg ED 1990 Histological and Histopathological Evaluation of the Testis, 1st Edition, Clearwater, FL, USA: Cache River Press.

Sreedharan S, Stephansson O, Schioth HB \& Fredriksson R 2011 Long evolutionary conservation and considerable tissue specificity of several atypical solute carrier transporters. Gene 478 11-18. (doi:10.1016/j. gene.2010.10.011)

Toshimori K \& Ito C 2003 Formation and organization of the mammalian sperm head. Archives of Histology and Cytology 66 383-396. (doi:10.1679/aohc.66.383)

Wang H, Wan H, Li X, Liu W, Chen Q, Wang Y, Yang L, Tang H, Zhang X, Duan $\mathrm{E}$ et al. 2014 Atg7 is required for acrosome biogenesis during spermatogenesis in mice. Cell Research 24 852-869. (doi:10.1038/ cr.2014.70)

Xiao N, Kam C, Shen C, Jin W, Wang J, Lee KM, Jiang L \& Xia J 2009 PICK1 deficiency causes male infertility in mice by disrupting acrosome formation. Journal of Clinical Investigation 119 802-812. (doi:10.1172/ JCl36230)

Xu X, Toselli PA, Russell LD \& Seldin DC 1999 Globozoospermia in mice lacking the casein kinase II alpha' catalytic subunit. Nature Genetics 23 118-121. (doi:10.1038/12729)

Yao R, Ito C, Natsume Y, Sugitani Y, Yamanaka H, Kuretake S, Yanagida K, Sato A, Toshimori K \& Noda T 2002 Lack of acrosome formation in mice lacking a Golgi protein, GOPC. PNAS 99 11211-11216. (doi:10.1073/ pnas.162027899)

Yassine S, Escoffier J, Martinez G, Coutton C, Karaouzene T, Zouari R, Ravanat JL, Metzler-Guillemain C, Lee HC, Fissore R et al. 2015 
Dpy19l2-deficient globozoospermic sperm display altered genome packaging and DNA damage that compromises the initiation of embryo development. Molecular Human Reproduction 21 169-185. (doi:10.1093/molehr/gau099)

Yildiz Y, Matern H, Thompson B, Allegood JC, Warren RL, Ramirez DM, Hammer RE, Hamra FK, Matern S \& Russell DW 2006 Mutation of beta-glucosidase 2 causes glycolipid storage disease and impaired male fertility. Journal of Clinical Investigation 116 2985-2994. (doi:10.1172/ $\mathrm{JCl} 29224)$

Yoshida T, Ioshii SO, Imanaka-Yoshida K \& Izutsu K 1994 Association of cytoplasmic dynein with manchette microtubules and spermatid nuclear envelope during spermiogenesis in rats. Journal of Cell Science $\mathbf{1 0 7}$ 625-633.

Received 24 November 2015

First decision 4 January 2016

Revised manuscript received 5 April 2016

Accepted 21 April 2016 